\title{
THE EFFECT OF VERNONIA CALVOANA EXTRACT ON SOME HAEMATOLOGICAL INDICES IN ACETAMINOPHEN TREATED MALE WISTAR RATS
}

\author{
GODWIN ENEJI EGBUNG, ITEM JUSTIN ATANGWHO, OCHUOLE DIANA ODEY AND \\ SUNDAY AGBA BISONG
}

(Received 12 June 2017; Revision Accepted 2 August 2017)

\begin{abstract}
The effect of Vernonia calvoana extract on some haematological indices in acetaminophen (paracetamol) treated albino Wistar rats was investigated in this study. Thirty-five (35) albino Wistar rats weighing 100-150g were randomly assigned into five (5) groups of seven rats each. Group 1 was the normal control ( Normal saline), group 2 received normal saline after treating with $2 \mathrm{~g} / \mathrm{kg}$ Acetaminophen (Paracetamol) via oral gavage, group 3 was treated with $200 \mathrm{mg} / \mathrm{kg}$ body weight of V.C, group 4 received $400 \mathrm{mg} / \mathrm{kg}$ body weight of V.C and group 5 was administered $100 \mathrm{mg} / \mathrm{kg}$ body weight of Vitamin E. All treatments were done orally gavaged and lasted for twenty-one days. At the end of the treatment period, animals were euthanized using chloroform vapours, and blood was collected via cardiac puncture. The blood was collected and used for evaluation of some haematological indices. Results indicated significant $(p<0.001)$ increase in red blood cell count, haemoglobin and packed cell volume in the $400 \mathrm{mg} / \mathrm{kg}$ body weight Vernonia calvoana extract treated group compared with acetaminophen treated group. Similarly, platelet count, Lymphocytes and white blood cell count were markedly increased in the $200 \mathrm{mg} / \mathrm{kg} \mathrm{VC,} 400 \mathrm{mg} / \mathrm{kg} \mathrm{VC}$ and vit Etreated groups $(p<0.05)$. We, therefore, conclude that ethanolic leaf extract of Vernonia calvoana administered at $400 \mathrm{mg} / \mathrm{kg}$ body weight possess anti-anaemic properties.
\end{abstract}

KEYWORDS: Acetaminophen, anti-anaemia, Wistar rats and Vernonia calvoana

\section{INTRODUCTION}

Acetaminophen (Paracetamol - PCM) is one of the most commonly found drugs in a lot of homes. It is the most widely used and available analgesic in Nigeria. As a result, there is very high potential for abuse and an eventual overdose of the drug (Sheen et al., 2002). Paracetamol toxicity due to overdose is one of the most common causes of poisoning worldwide (Gunnell, et al., 2000). Acute paracetamol overdose can result in potentially dangerous liver and kidney failure in both human and experimental animals and may result in death in extreme cases (Lorz et al., 2004). The kidney happens to be the second target organ of paracetamol toxicity, though nephrotoxicity may exist independent of hepatoxicity following overdose (Gulnaz, et al., 2010).

The role of kidney in erythropoiesis cannot be over emphasised. Most ethnobotanicals has been reported to boost haemoglobin levels in animals It, therefore, becomes imperative to investigate the possible haematopoietic activity of Vernonia calvoana leaf extract in acetaminophen-induced Wistar rats.

Renal impairment is directly associated with quite a number of haematopoietic changes/distortions. There is a strong correlation between anaemia and the degree of renal dysfunction, with the major cause being the failure of kidneys to produce erythropoietin (Alpers, 2004). Anaemia is referred to as an ordinary complication of chronic kidney disease or chronic renal failure (progressive decreased loss of renal function) because, due to damage or loss of function of the kidney, the epithelial cells cannot efficiently produce the erythropoietin required for erythropoiesis to take place. This will result in the reduction of red blood cell (RBC) count (Hodges et al., 2007). Erythropoietin is a hormone produced by epithelial renal cells. It regulates red blood cell production and assists in the maintenance of the viability and integrity of the cells (Suresh et al., 2012)

Medicinal plants have played an important role in the abatement of toxic substances in the human body. They also function as vital hypolipidemic agents (Luo et al., 2004). There are so many plants with potent medicinal properties in the tropics, with Vernonia being a common genus of such plants. Tende et al. (2013) reported the non erythropoietic effects of Vernonia amygdalina extracts in Wistar rats. The most commonly eaten ones are Vernonia calvoana, Vernonia amygdalina, with the former being the plant of interest. Vernonia calvoana belongs to the Asteraceae family. It is commonly called "Ekeke leaf" and "Uchu nyin" respectively by the indigenes of the central and northern senatorial districts of Cross-River State of Nigeria (Igile et al., 2013, Egbung et al., 2016). The emphasis on Vernonia amygdalina has resulted in the neglect of other less utilised species that may have some ethnomedicinal properties. Vernonia calvoana has been

Godwin Eneji Egbung, Department of Biochemistry, University of Calabar, P.M.B 1115, Calabar, Nigeria. Item Justin Atangwho, Department of Biochemistry, University of Calabar, P.M.B 1115, Calabar, Nigeria. Ochuole Diana Odey, Department of Biochemistry, University of Calabar, P.M.B 1115, Calabar, Nigeria. Sunday Agba Bisong, Department of Physiology, University of Calabar, P.M.B 1115, Calabar, Nigeria. 
sparsely investigated compared to other Vernonia species. The anti-oxidant properties of the leaves as well as the inflorescents of Vernonia calvoana has been established (Igile et al., 2013, Egbung et al., 2016). However, there is little or no information on the erythropoietic potentials of the extract of Vernonia calvoana in acetaminophen treated Wistar rats. The present study was designed to fill this information gap.

\subsection{MATERIALS AND METHODS}

\subsection{MATERIALS}

2.1.1 Procurement of Leaves, Rat chow and Paracetamol (Acetaminophen)

Fresh Vernonia calvoana leaves were purchased from a local market in Ugep town in Yakurr Local Government Area of Cross-River State, Nigeria. The rat chow was bought from Pfizer Livestock Feeds, Aba, Abia State, Nigeria. The composition of the commercial rat pellet is shown in appendix (A). The leaves were authenticated by Mr Frank Apojeye of the Department of Botany, University of Calabar, Calabar, Cross-River State, Nigeria, and voucher number BOT/VC/2/2015 deposited in the herbarium of the same department. Paracetamol manufactured by Emzor pharmaceuticals was purchased from Anijah Pharmacy, Etta Agbor Road, Calabar, Cross River State.

\subsubsection{Preparation of ethanolic extract}

The leaves were washed thoroughly to remove dust and other forms of dirt and afterwards air dried at room temperature $\left(27^{0} \mathrm{C} \pm 2^{0} \mathrm{C}\right)$ for seven days to remove moisture until completely dry. The dried leaves were blended to a fine powder using a dry Moulinex super blender and stored in air-tight containers. $1.5 \mathrm{~kg}$ of the powder was weighed using an electronic scale and afterwards soaked in $2000 \mathrm{ml}$ of methanol and dichloromethane $(1: 1, \mathrm{v} / \mathrm{v})$ in a ratio of $3: 4$, i.e. (powder/solvent). To allow for proper mixing of the powder and the solvent, the mixture was put in the blender, agitated and then put in air-tight containers. The containers holding the mixtures were kept in the refrigerator at a temperature of $4^{0} \mathrm{C}$ for 48 hours. Filtration of the mixture was accomplished first by using a cheese cloth, followed by the Whatman no.1 filter paper $(24 \mathrm{~cm})$. The filtrate was concentrated using a rotary evaporator (model RE52A, China) to $10 \%$ of its original volume at a temperature of $37^{\circ} \mathrm{C}-40^{\circ} \mathrm{C}$. It was then concentrated to complete dryness in a water bath. The extract was afterwards refrigerated at $2-8^{0} \mathrm{C}$ until when required for administration.

\subsubsection{Experimental animals and design}

Thirty-five albino Wistar rats comprising of both sexes weighing between 100 to $150 \mathrm{~g}$, were obtained from a disease-free stock of the animal house, Department of Zoology, University of Calabar, Calabar. The animals were acclimatized for two weeks on pelletized rat chow and water provided ad libitum and were maintained under standard housing condition of adequate ventilation and room temperature of $28^{\circ} \mathrm{C} \pm$ $2{ }^{\circ} \mathrm{C}$ and relative humidity of $46 \% \pm 5 \%$ and a natural 12 hour light - dark regimen in the Biochemistry Department's animal house, where they were kept for the period of the experiment. Permission and approval for the use of the animals to carry out the study according to approved protocol was obtained from the Faculty of Basic Medical Sciences Ethical Committee, University of Calabar, Calabar. The animals were weighed and assigned randomly to five groups of seven rats each based on weight. All the groups were allowed free access to pelletized rat chow and clean water. See experimental design below:

Table 1: Experimental Treatment Groups

\begin{tabular}{lll}
\hline Group & Number of animals & Treatment \\
\hline Group 1 & 7 & $2 \mathrm{~g} / \mathrm{kg}$ bwt of Paracetamol only \\
Group 2 & 7 & $2 \mathrm{~g} / \mathrm{kg}$ of Paracetamol $+200 \mathrm{mg} / \mathrm{kg} \mathrm{bwt} \mathrm{of} \mathrm{V.C}$ \\
Group 3 & 7 & $2 \mathrm{~g} / \mathrm{kg}$ of Paracetamol $+400 \mathrm{mg} / \mathrm{kg}$ bwt of V.C \\
Group 4 & 7 & $2 \mathrm{~g} / \mathrm{kg}$ of Paracetamol $+100 \mathrm{mg} / \mathrm{kg}$ bwt of Vit. E \\
Group 5 & 7 & \\
\hline
\end{tabular}

VC = Extract of Vernonia calvoana, Vit. E = Vitamin E, bwt = Body weight

\subsubsection{Extract and drug administration}

The doses $(200 \mathrm{mg} / \mathrm{kg}$ and $400 \mathrm{mg} / \mathrm{kg}$ ) used were based on the predetermined $L D_{50}$ values obtained using the method of Lorke (1983). The dose of $2 \mathrm{~g} / \mathrm{kg}$ bwt of paracetamol was based on the report of Suchismita et al. (2015). The extract was diluted in normal saline, which acted as the vehicle and administered orally through gastric intubation accordingly. The control animals received $0.2 \mathrm{ml}$ of normal saline. Treatment period with the Vernonia calvoana leaf extract lasted for a period of 21 days. The animals were fasted 12 hours overnight prior to the time of sacrifice. The animals were euthanised with chloroform and blood samples collected via cardiac puncture. 


\subsection{METHODS}

\subsubsection{Haematological indices determination}

Whole blood was collected from each experimental animal through cardiac puncture and put into to sterile Ethylenediamine tetra acetic acid, EDTA sample tubes and used for determination of haematological indices (Haemoglobin, red blood cell, white blood cell, platelet and packed cell volume). The auto analyzer was used for the estimations.

\subsubsection{Statistical Analysis}

Data obtained were analysed using one-way analysis of variance and differences between pairs of groups were determined using posthoc multiple comparisons. Results were expressed as mean \pm standard error of mean (SEM). Data were considered significant at $p<0.05, p<0.01$ and $p<0.001$. Computer software SPSS version 17.0 and Microsoft excel (2007 version) were used for analysis.

\subsection{Results}

Results of the haematological effects of Vernonia calvoana extracts in Acetaminophen (PCM)treated Wistar rats are presented in figures $1-6$. The untreated nephrotoxic group indicated a significantly lower mean RBC count at $p<0.001$, compared to the normal control group. The group treated with $200 \mathrm{mg} / \mathrm{kg}$ bwt of the extract had a slightly lower RBC count, significant at $p<0.01$ compared to the normal control. The group treated with $400 \mathrm{mg} / \mathrm{kg}$ of the extract bwt showed a significantly higher RBC count compared to the untreated nephrotoxic group at $p<0.001$. In comparison with the group treated $200 \mathrm{mg} / \mathrm{kg}$ bwt, the $400 \mathrm{mg} / \mathrm{kg}$ bwt treated group showed a significant increase in RBC count at $p<0.01$, indicating a dosedependent increase. The vitamin $E$ treated group showed a significantly lower RBC count compared to the normal control and the group treated $400 \mathrm{mg} / \mathrm{kg}$ bwt at $\mathrm{p}$ $<\quad 0.01 \quad$ respectively.

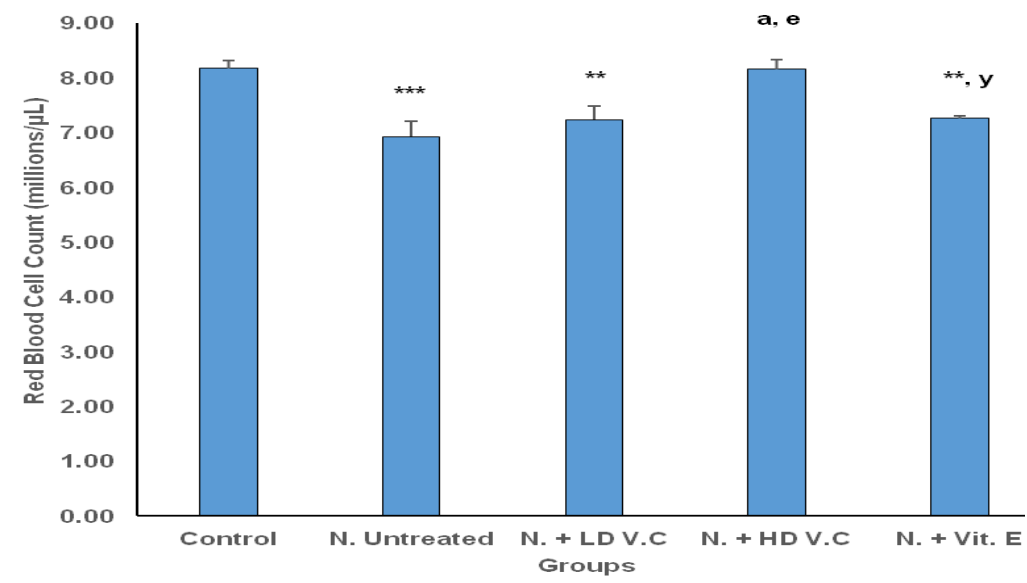

Fig 1: Effect of $V$.calvoana extract on Red blood cell count in paracetamol treated rats. Values are mean $\pm S E M, n=$ $5 .{ }^{* *} p<0.01,{ }^{* * *} p<0.001$ vs control, $a=p<0.001$ vs N.untreated, $e=p<0.01$ vs $N+$ LD V.C, $y=p<0.01$ vs N + HD V.C

Figure 2 shows a comparison of haemoglobin $(\mathrm{Hb})$ concentration across the experimental groups. Group 2 shows a significant decrease at $\mathrm{p}<0.05$ in $\mathrm{Hb}$ level compared to group 1. Also, the $\mathrm{Hb}$. level of the group treated with $400 \mathrm{mg} / \mathrm{kg}$ bwt of the extract (group 4) shows a significant increase at $p<0.05$ compared to group 2 (nephrotoxic untreated group). Vitamin E treated group (group 5) revealed a significantly lower $\mathrm{Hb}$. concentration compared to the normal control at $p<$ 0.05 and a lower $\mathrm{Hb}$. level compared to group 4 at $\mathrm{p}<$ 0.05 . The packed cell volume (PCV) result (Figure 3 ) showed a significant $(p<0.001)$ decrease in group 2 compared to group 1 . Similarly, group 3 indicated a lower PCV value, significant at $p<0.01$ compared to the normal control as well. There was a significant increase in PCV at $p<0.001$ in group 4 when compared to group 2. A dose-dependent increase in PCV was observed group 4 showed a significant increase in PCV at $p<$ 0.001 compared to group 3. PCV of group 5 was significantly lower at $p<0.001$ compared to the normal control and group 4 respectively.

Treatment with $400 \mathrm{mg} / \mathrm{kg}$ body weight V.C indicated a significantly higher value of lymphocytes at $p$ $<0.001$ relative to group 2 (Figure 4). Group 3 had a lower lymphocyte count significant at $p<0.01$ compared to the normal control and a significantly higher value at $p$ $<0.01$ as well when compared to paracetamol - induced group (group 2). Group 5 shows a significantly lower value at $p<0.001$ relative to the control as well as group 2 and 4 at $\mathrm{p}<0.01$ 


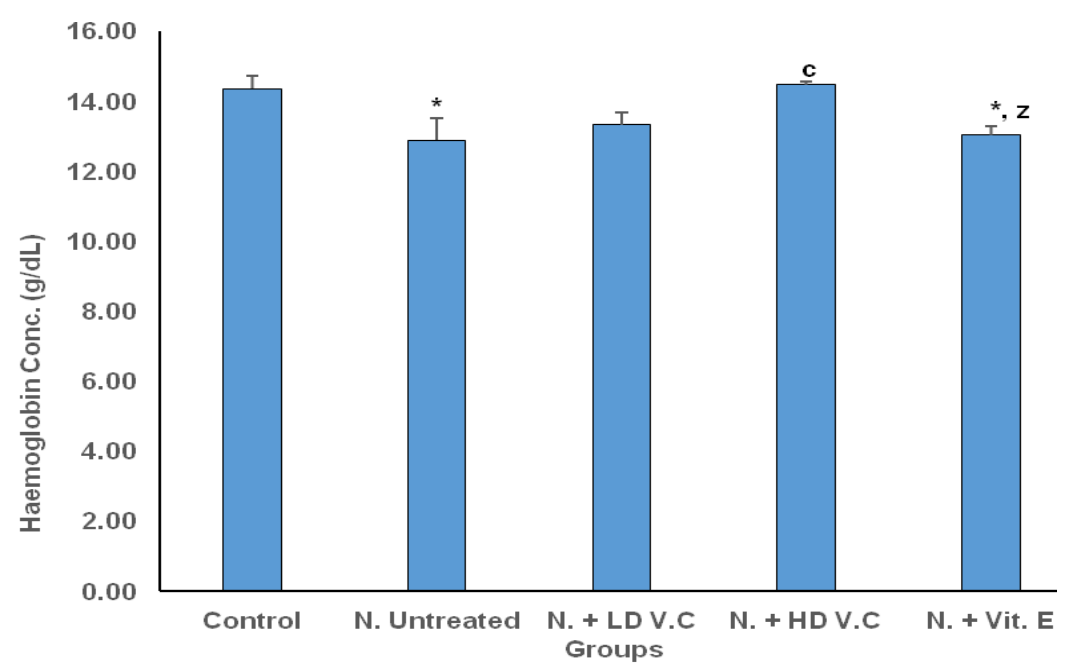

Fig. 2: Effect of V.calvoana extract on haemoglobin concentration in paracetamol treated rats. Values are mean \pm SEM, $n=5 .{ }^{*} p<0.05$ vs control, $c=p<0.05$ vs N.untreated, $z=p<0.05$ vs $N+$ HD V.C

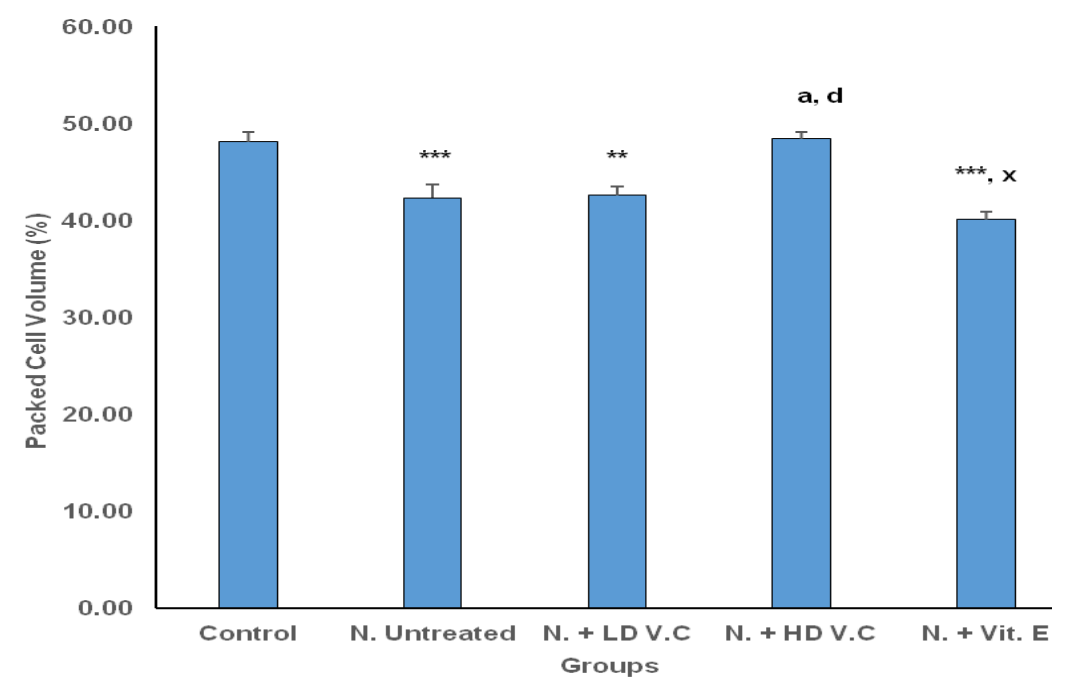

Fig. 3: Effect of V.calvoana extract on packed cell volume in paracetamol treated rats. Values are mean $\pm S E M, n=$ $5 .{ }^{*} p<0.01,{ }^{* \star *} p<0.001$ vs control, $a=p<0.001$ vs N.untreated, $d=p<0.01$ vs $N+$ LD V.C, $x=p<0.01$ vs N + HD V.C 


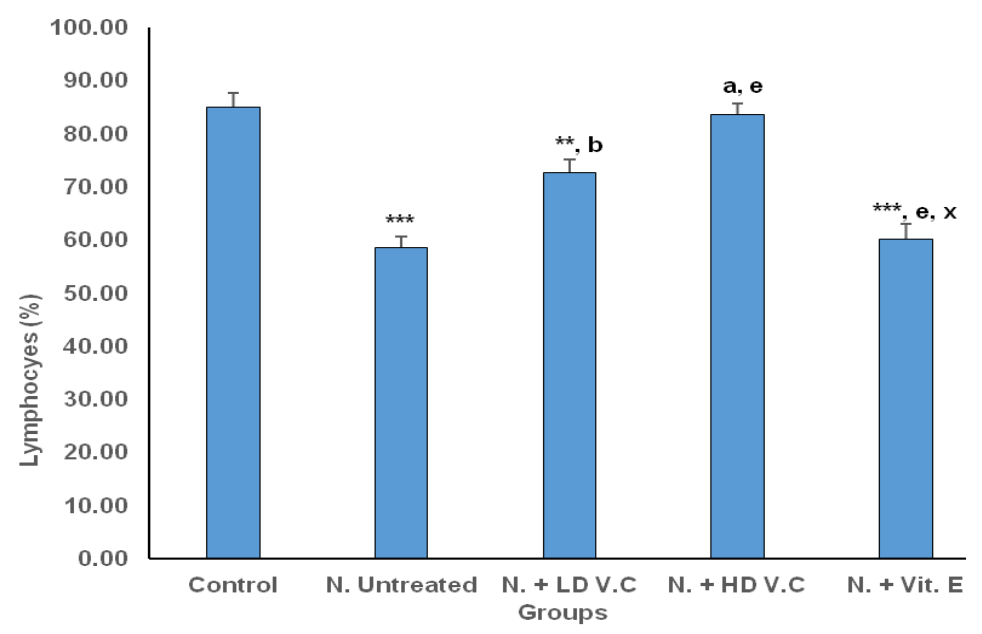

Fig 4: Effect of $V$.calvoana extract on lymphocyte count in paracetamol treated rats. Values are mean $\pm S E M, n=5$. ${ }^{* *} p<0.01,{ }^{* * *} p<0.001$ vs control, $a=p<0.001, b=p<0.01$ vs $N$. untreated, $e=p<0.01$ vs $N+$ LD V.C, $x=p<0.01$ vs $N+$ HD V.C

The platelet counts (figure 5) showed a significant $(p<0.001)$ decrease in the paracetamolinduced compared to the normal control. A significant $(p$ $<0.001$ ) increase in platelet count was observed in group 3 relative to group 2. The $400 \mathrm{mg} / \mathrm{kg} \mathrm{V.C} \mathrm{treated}$ group indicated a significantly increased platelet count at $(p<0.001)$ compared to the normal control and group 2 respectively. The same pattern was observed when compared to group 3. Group 5 showed a significantly higher platelet count at $p<0.05$ when compared to groups $\quad 1$ and 2 respectively.

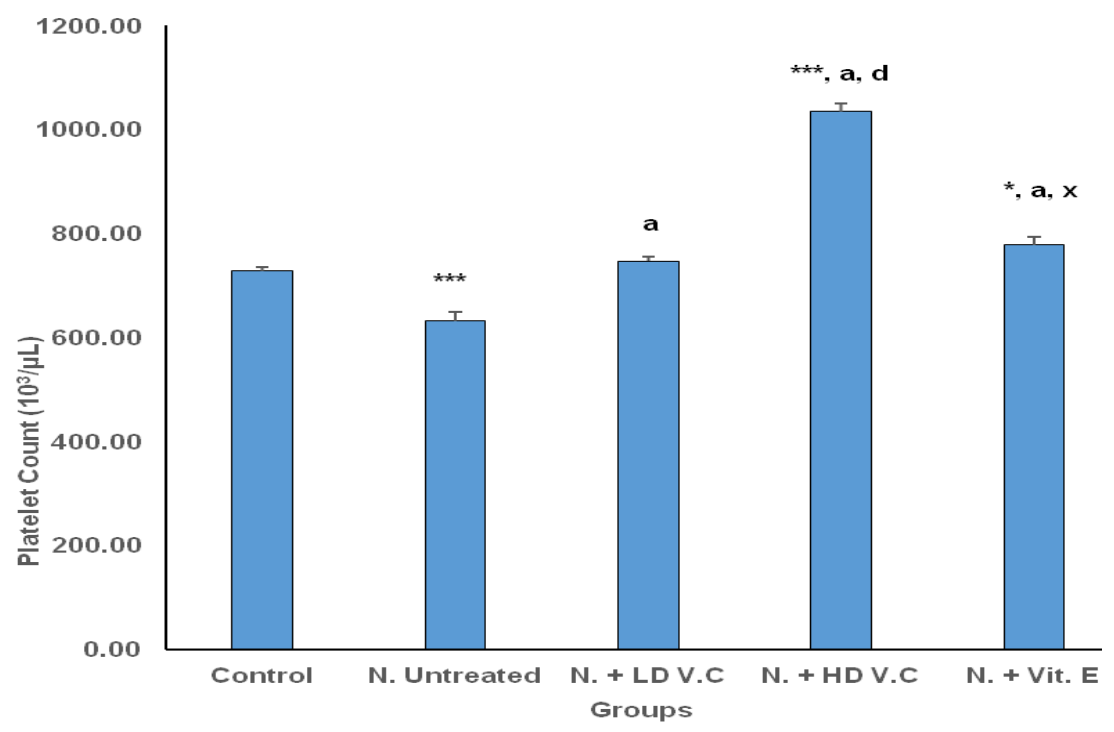

Fig. 5: Effect of $V$.calvoana extract on platelet count in paracetamol treated rats. Values are mean $\pm S E M, n=5$. ${ }^{*} p<0.05,{ }^{* * *} p<0.001$ vs control, $a=p<0.001$ vs $N$. untreated, $d=p<0.001$ vs $N+$ LD V.C, $x=p<0.001$ vs $N+$ HD V.C 
The white blood cell count (Figure 6) in the untreated nephrotoxic group (group 2) had a significantly lower WBC count at $p<0.001$ compared with the normal control. The WBC count of the group treated with $400 \mathrm{mg} / \mathrm{kg}$ bwt of the extract increased significantly at $\mathrm{p}$ $<0.05$ compared to the normal control and group 2 respectively. Similarly, the group treated with vitamin $E$ (group 5) had a higher WBC count significant at $p<0.01$ relative to group 1 . WBC count of group 5 also increased significantly at $p<0.001$ compared to groups 2 and 3 respectively.

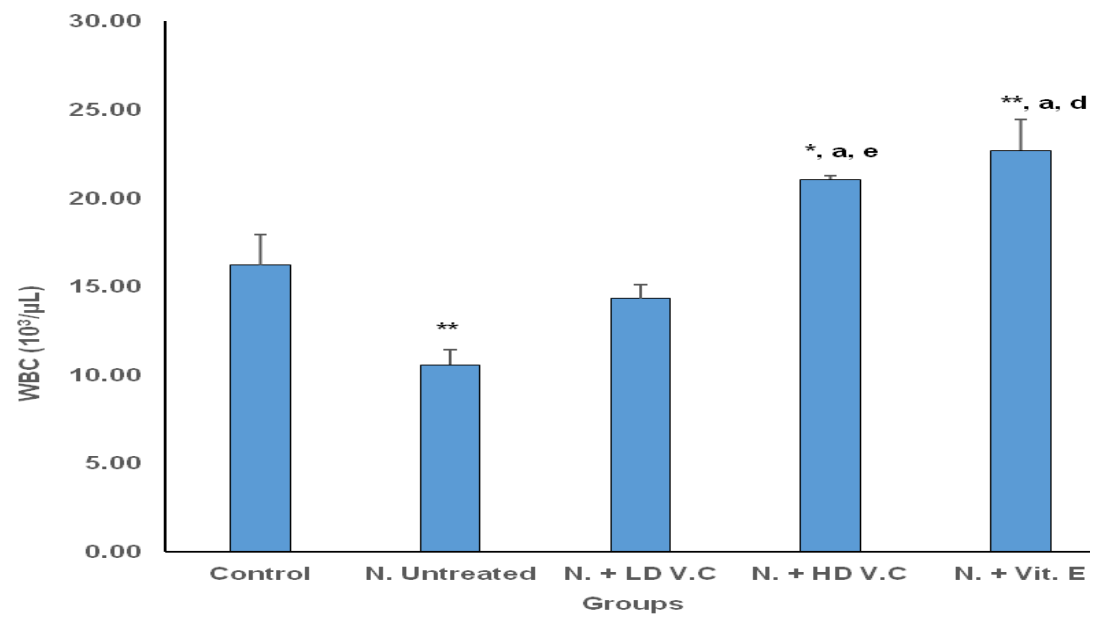

Fig. 6: Effect of $V$.calvoana extract on the white blood cell count in paracetamol treated rats. Values are mean $\pm S E M$, $n=5 .{ }^{*} p<0.05,{ }^{* *} p<0.01$ vs control, $a=p<0.001$ vs $N$. untreated, $e=p<0.001, d=p<0.001$ vs $N+$ LD V.C

\subsection{DISCUSSION}

Acetaminophen (paracetamol) has been reported to exert toxicity in Wistar rats at $2000 \mathrm{mg} / \mathrm{kg}$ bwt or $2 \mathrm{~g} / \mathrm{kg}$ bwt (Suchismita et al., 2015). The untreated nephrotoxic group (group 2) that received $2 \mathrm{~g} / \mathrm{kg}$ of PCM showed a decrease in red blood cell count, $\mathrm{Hb}$ concentration, $\mathrm{PCV}$, and platelet count compared to the normal control and the Vernonia calvoana extract treated groups. A strong correlation has been established between anaemia and the degree of renal dysfunction, with the major cause being the failure of the kidneys to produce erythropoietin (Alpers, 2004). Renal impairment has been linked directly to a number of haematological distortions. Therefore, the reduced red blood cell count could be as a result of a compromised erythropoietin production as a result of damage due to acetaminophen overdose. Erythropoietin is also implicated in the humoral regulation of the platelet mass (Suresh et al., 2012). However, the group treated with $400 \mathrm{mg} / \mathrm{kg}$ bwt of the extract showed an improvement in erythrocyte count, $\mathrm{Hb}$ concentration, $\mathrm{PCV}$ and platelet count. This indicates a positive haematopoietic effect that is contrary to the findings of Tende et al. (2013) that investigated a sister specie, Vernonia amygdalina in Wistar rats. The haematopoietic activity of Vernonia calvoana extracts which is comparable to Vitamin $E$ treated group may be attributed to the proximate/chemical composition of the plant especially the flavonoids. Vitamin $\mathrm{E}$ is a synthetic antioxidant drug that prevents oxidative stress induced damage in tissues of living organisms. Igile et al., (2013) reported appreciable amounts of protein, vitamins, folic acid and minerals. Earlier reports also indicated that protein-rich diets have the ability to increase PCV and $\mathrm{Hb}$ concentration in human and animal studies (Bolarinwa et al., 1991, Alada et al., 2004, Alada, 2000).

The lymphocyte and white blood cell count of the nephrotoxic untreated group decreased significantly. This agrees with a human study report of (Arun et al., 2012), where patients who suffered from a progressive deterioration of their renal function experienced a decline in their immune status, following a decrease in white blood cell count. The precise mechanism of action behind this reduction has not been fully understood. The groups treated with the extract showed a dosedependent increase in lymphocyte and leukocyte count. The leucocyte count increase could be attributed to the presence of zinc in the plant in appreciable amounts, which is capable of stimulating the formation of white blood cells according to (Claude and Paule, 1979). The increase in lymphocyte count could also imply possible immune boosting potentials since lymphocytes are known to have the ability to fight diseases.

\section{CONCLUSION}

From the results obtained in this study, it is safe to further confirm that the ethanol leaf extract of 
Vernonia calvoana has shown the potential to possibly reverse the haematological imbalance that occurred due to paracetamol-induced toxicity .We therefore suggests that the extract possess anti-anaemic/immune boosting properties at $400 \mathrm{mg} / \mathrm{kg}$ body weight.

\section{REFERENCES}

Alada, A. R. A., 2000. The haematological effect of Telfara occidentalis diet preparation in the rat. Africana Journal of Biomedical Research, 3, 185-186.

Alada, A. R. A., Akande, O. O and Ajayi, F., 2004. Effect of Soya bean diet preparation on some haematological and biochemical indices in the rat. Africana Journal of Biomedical Research, 7, $71-74$

Alpers, C. E., 2004. The kidney. In: Vinay Kumar, Abul, K. A. \& Nelson Fasto. Robbins Pathologic basis of disease, $7^{\text {th }}$ edition. Elsevier Incorporated, 20, $960-965$.

Arun, S., Prabhu, M. V., Chowta, N. K and Bengrre, M.

L., 2012. The hameatological pattern of the patients with chronic kidney disease in a tertiary care setup in South India. Journal of Clinical and Diagnostic Research, 6(6), 1003-1006.

Bolarinwa, A. F., Oyebola, D. D. O and Akindeinde, G. B., 1991. Effect of malnutrition on basal and induced gastric acid secretion. Nigerian Journal of Physiological Science, 5(2), 144-148.

Claude, B and Paule, S., 1979. The manual of Natural living. ( ${ }^{\text {st }}$ Edn). Guildford: Biddles Ltd., 98-101.

Egbung, G. E., Atangwho, I. J., Kiasira, Z. B., Iwara, A. I and Igile, G. O., 2016. Antioxidant activity of the inflorescents of Vernonia calvoana growing in Yakurr Local Government Area of Cross River State, Nigeria. Gobal Journal of Pure and Applied Sciences 22(2):141-146.

Gulnaz, H., Tahir, M., Muni, B and Sami, W., 2010. Protective effects of garlic oil on acetaminophen induced nephrotoxicity in male wistar rats. Biomedical, 29, 9-15.

Gunnell, D., Murray, V and Hawton, K., 2000. Use of paracetamol (Acetaminophen) for suicide and non-fatal poisoning: Worldwide pattern of use and misuse. Suicide and Life-threatening Behaviour, 30(4), 313-326.
Hodges, V. M., Rainey, S., Lappin, T. R and Maxwell, A. P., 2007. Pathophysiology of anemia and erythrocytes. Critical Reviews in Oncology Hematology, 64, 139-158.

Igile, G. O., Iwara, I. A., Mgbeje, B. A., Uboh, F. E and Ebong, P. E., 2013. Phytochemical, proximate and nutrient composition of Vernonia calvoana hook (Asterecea). A Green-Leafy vegetable in Nigeria. Journal of Food Research, 2, 6.

Lorke, D., 1983. A new approach to practical acute toxicity testing.Archives of Toxicology,54,274 287.

Lorz, C., Justo, P., Sanz, A., Subira, D., Egido, J and

Oritz, A., 2004. Paracetamol-induced renal tubular injury: a role for ER stress. Journal of American Society of Nephrology, 15, 380-389.

Luo, Q., Cai, Y., Yan, J., Sun, M and Corke, H., 2004. Hypoglycemic and hypolipidemic effects and antioxidant activity of fruit extracts from lyceum barbarum. Elsevier Journal of Life Sciences, 76(2), 137-149

Sheen, C. L., Dillon, J, F., Bateman, D. N., Simpson, K. $\mathrm{J}$ and MacDonald, T. M., 2002. Paracetamol toxicity: epidemiology, prevention and cost to the healthcare system. Oxford Journal of Medicine, 95(9), 609-619

Suchismita, R., Shrabani, P., Koushik, D., Arpita, M., Shreya, M., Arpita, P., Animesh, S., Banadeb, S and Dilip, K. N., 2015. Acetaminophen Induced Kidney Failure in Rats: A Dose Response Study. Journal of Biological Sciences, 15: 187-193.

Suresh, M., Mallikarjuna, R. N., Sharan, S. M., Hari, K. B., Sharavya, K. G and Chandrasekhar, M., 2012. Hematological changes in chronic renal failure. International Journal of Scientific and Research Publications, 2(9).

Tende, J. A., Eze, E. D and Tende, Y. A., 2013. Haematological effects of aqueous extract of Vernonia amygdalina in wistar rats .Scientific Journal of Biological Sciences 2(3), 62-67. 